\title{
AMÉRICA LATINA E ABYA YALA NO ENSINO DE HISTÓRIA ESPANHOL: $O$ “DESCOBRIMENTO”, A CONQUISTA E AS CONTROVÉRSIAS DA LEYENDA NEGRA
}

\author{
Carlos Renato Carola ${ }^{1}$ \\ Rafael Valls Montés²
}

\section{RESUMO}

O trabalho explicita as representações contemporâneas da História da América no ensino de História na Espanha. Explicita e problematiza as configurações textuais e iconográficas que pretendem ensinar uma história do "descobrimento", da conquista e da colonização da América. Usou-se a metodologia da pesquisa bibliográfica e de campo, com técnica de fichamento e observações analíticas de obras historiográficas contemporâneas, livros didáticos e lugares de memória (museus e monumentos históricos). Em relação aos manuais didáticos, foram selecionados e analisados 18 livros de ensino de História editados por seis editoras no período de 2000 a 2015. Analisou-se a história do "descobrimento" e da colonização na perspectiva teórica da decolonialidade (DUSSEL, 1994, LANDER, 2005; MIGNOLO, 2007).

Palavras-chave: ensino de História, descobrimento, América Latina, Abya Yala.

${ }^{1}$ Universidade do Extremo Sul Catarinense (Unesc), Criciúma/SC, Brasil.

${ }_{2}^{2}$ Universidad de Valencia (UV), Madrid, Espanha. 


\title{
AMÉRICA LATINA Y ABYA YALA EN LA ENSEÑANZA \\ DE LA HISTORIA DE ESPAÑA: EL "DESCUBRIMIENTO", LA CONQUISTA Y LAS CONTROVERSIAS DE LA LEYENDA NEGRA
}

\section{RESUMEN}

El trabajo describe las tendencias contemporáneas de Historia de América en la enseñanza de la Historia en España. Analiza el texto y las representaciones iconográficas que pretenden enseñar una historia del "descubrimiento", de la conquista y de la colonización de América. La investigación se utilizó de la metodología de la investigación bibliográfica y de campo, con análisis de obras historiográficas contemporáneas, libros de textos y observaciones de lugares de memoria (museos y monumentos históricos). En relación a los manuales didácticos, fueran seleccionados y analizados 18 libros de textos de la enseñanza de Histórica (Educación Secundaria y Bachillerado) publicados por seis editores desde 2000 hasta 2015. Se analizó la historia del "descubrimiento" y de la colonización en la perspectiva teórica de la decolonialidad (DUSSEL, 1994, LANDER, 2005; MIGNOLO, 2007).

Palabras clave: enseñanza de la historia, descubrimiento; América Latina, Abya Yala.

\section{LATIN AMERICA AND ABYA YALA IN TEACHING SPANISH HISTORY: THE "DISCOVERY", THE CONQUEST AND CONTROVERSIES OF THE BLACK LEGEND}

\begin{abstract}
The paper explains the contemporary representations of America's History in the teaching of History in Spanish. It explains and problematizes textual and iconographical configurations that intend to teach a history of the "discovery", conquest and colonization of America. In methodological terms, one used the methodology of bibliographical and field research, with annotation technique and analytical observations of contemporary historiographical papers, textbooks and places of memory (museums and historical monuments). As for learning guides, 18 History teaching books edited by six publishers were selected and analyzed from 2000 to 2015. One observes the history of "discovery" and colonization under the theoretical perspective of decoloniality (DUSSEL, 1994; LANDER, 2005; MIGNOLO, 2007).
\end{abstract}

Keywords: teaching of History, discovery, Latin America, Abya Yala. 


\section{AMERIQUE LATINE ET ABYA YALA DANS L'ENSEIGNEMENT DE L'HISTOIRE ESPAGNOLE: LA DECOUVERTE, LA CONQUETE ET LA CONTROVERSE LEGEND BLACK}

\section{RÉSUMÉ}

Le travail explique les représentations contemporaines de l'histoire Amerique Latine dans l'enseignement en Espagne. Explique et analyse les paramètres textuels et iconographiques qui prétendent enseigner une histoire de la découverte, de la conquête et la colonisation de l'Amérique. Il a utilisé la méthodologie de la recherche bibliographique et sur le terrain avec le rapport book observations techniques et analytiques des ouvrages historiques contemporains, des manuels et des lieux de mémoire (musées et monuments). En ce qui concerne les manuels ont été sélectionnés et analysés 18 manuels d'histoire édités par six éditeurs 2000-2015. Examine l'histoire de la "découverte" et de la colonisation dans la perspective théorique d'decoloniality (DUSSEL, 1994; LANDER, 2005; MIGNOLO, 2007).

Mots-clés: enseignement d'Histoire, découverte, l'Amérique Latine, Abya Yala. 


\section{INTRODUÇÃO}

Nosso propósito geral é mostrar como se representa a História da América no ensino e na historiografia espanhola atualmente. Neste artigo, nos delimitamos a explicitar e problematizar as configurações dos conceitos clássicos que projetam uma paisagem histórica no período inicial da modernidade europeia: os povos indígenas, o "descobrimento", a conquista e a colonização. 3 Os dados empíricos da investigação foram coletados e observados na Espanha, no período de janeiro a outubro de 2016. Selecionamos 18 livros didáticos editados no período de 2000 a 2015 e três livros publicados na década de 1990, para fins de comparação. Analisamos os manuais de ensino de História publicados pelas principais editoras que produzem livros didáticos para o sistema escolar espanhol e um conjunto de obras historiográficas (historiografia conservadora e crítica) que abordam o tema da conquista da América. Embora não seja possível, neste espaço, explicitar especificamente o resultado de todos os procedimentos metodológicos realizados, informamos que nosso campo de observação abrangeu também as representações da América nos lugares da memória oficial: centros históricos, monumentos e museus em Madrid, Barcelona, Valência, Granada, Córdoba, Murcia, Oviedo, Cádiz, Sevilha, Valladolid e Tordesilhas.

No âmbito geral da pesquisa, observamos analiticamente as visões e representações da História da América em relação a três períodos históricos, dividindo o processo da investigação em três etapas: 1) Índios/povos indígenas, "descobrimento", conquista e colonização do Nuevo Mundo; 2) "Emancipação" ou "independência" das colônias da América Espanhola no século XIX; 3) Temas predominantes da história dos Estados Unidos (EUA) e América Latina

\footnotetext{
3 Usamos o termo "descobrimento" entendendo que se trata de um conceito indissociável dos conceitos de conquista e colonização da América; e usamos "aspas" na palavra "descobrimento" para expressar nossa discordância em relação ao sentido colonialista da "descoberta", uma vez que se tratou muito mais de um encobrimento, como ressalta Enrique Dussel (1994).
} 
no século XX.4 Neste artigo apresentamos apenas os resultados específicos relacionados à história do "descobrimento" e colonização da América presente nas obras historiográficas e nos manuais didáticos.

Para conhecer melhor as configurações atuais da cultura espanhola, também observamos outras fontes e outros espaços educativos, entre os quais: leituras regulares de jornais (El País e El Mundo) e revistas de circulação nacional (El País Semanal, Clio, Desperta Ferro); filmes e programas televisivos. 5 Estudamos ainda a história do processo de formação do sistema educacional espanhol, com base na obra do professor Antonio Viñao (2004), que gentilmente nos facilitou o acesso à Biblioteca de História da Educação da Faculdade de Educação de Murcia.

Fizemos nosso percurso de estudo e pesquisa no território espanhol com base em três orientações teórico-metodológicas. A perspectiva da Educação Libertadora de Paulo Freire (2009), a perspectiva que problematiza a relação de poder e dominação entre opressores e oprimidos; a educação que nos provoca um processo consciente de autocrítica e nos fornece ferramentas reflexivas para a compreensão crítica da moral dominante do sistema social (presente e/ou passado) e dos mecanismos que justificam/legitimam e naturalizam as desigualdades e injustiças sociais de classe, gênero e raça (FREIRE e SCHOR,

4 Em termos metodológicos, empregamos a técnica do fichamento e organizamos sete (7) quadros de referências, identificando e descrevendo visões e conceitos relacionados aos objetivos da pesquisa: Q1: Referencial teórico - categorias e conceitos de referência; Q2: Revisão bibliográfica - História da América, América Latina e Leyenda Negra na Historiografia Latino-americana e espanhola; Q3: História da América/América Latina/IberoAmérica no Ensino Básico Espanhol e Latino-americano; Q4: Documentos Históricos de Referência: Crónicas/Diários do "descobrimento", da conquista e da colonização - Cristóvão Colombo, Hernan Cortez, Francisco de Vitoria, Bartolomé de Las Casas, Felipe de Guamán Poma de Yala e Garcilaso de la Veja; Q5: Libros Didáticos Ensino de História - Educación Secundária Obligatória (ESO) y Bachirellato (Espanha, 2000-2015); Imagens do "descobrimento", conquista e colonização nos livros didáticos espanhóis; Q7: Descobrimento, Conquista e Colonização da América nos Lugares de Memória - Centros Históricos, Praças e Museus - Espanha (2016).

5 Não comporta neste espaço textual explicitar nossas observações analíticas sobre as concepções do "descobrimento" que se difunde nesses meios de comunicação e formação, mas salientamos que a visão de História da América que se propaga nesse ambiente cultural da sociedade espanhola é uma visão amplamente conservadora, ou seja, é a visão histórica do ponto de vista dos conquistadores/colonizadores. 
1986). A perspectiva da decolonialidade, campo de estudos sistematizado teoricamente a partir da década de 1990 por Edgardo Lander, Arthuro Escobar, Walter Mignolo, Enrique Dussel, Anibal Quijano, Fernando Coronil, Chaterine Walsh entre outros (BALLESTRIN, 2013, p. 97)6, com o objetivo de problematizar e denunciar a face obscura da modernidade eurocentrista: a colonialidade do poder, do ser e do saber. Durante os nossos procedimentos de análise e observação, também consideramos a perspectiva epistemológica de Abya Yala (América Indígena), uma atitude ética que reconhece a história, dignidade, os direitos e a pluralidade étnico-cultural dos povos indígenas (Cf. PORTO-GONÇALVES, 2009; SARANGO, 2009; LISBOA, 2014).7 Por que América Latina e Abya Yala? América Latina, ressalta Walter Mignolo (2007, p. 81), fue el nombre elegido para denominar la restauración de la "civilización" de la Europa meridional, católica y latina en América del Sur u, al mismo tiempo, reproducir las ausencias (de los indios y los africanos) del primer período colonial; e Abya Yala (América Pré-Hispânica) é a denominação assumida pelo movimento indígena e por intelectuais para expressar a visão de mundo e reivindicar a memoria e os direitos dos povos originários. (LISBOA, 2014, p. 518).

Organizamos o conteúdo do artigo em duas partes. Na primeira, explicitamos e problematizamos o significado do "descobrimento" e as controvérsias da Leyenda Negra nas obras historiográficas que se situam no

\footnotetext{
${ }^{6}$ Restrepo y Rojas (2010, p. 163) explicitam a perspectiva decolonial da seguinte forma: Por opción decolonial Mignolo (2007c: 213) entiende: (1) una analítica y una visión de futuro, es decir, una comprensión del presente y una formulación del porvenir. (2) La confluencia de múltiples proyectos políticos que son críticos del eurocentrismo (el cual se encuentra formulado en concepciones cristianas, liberales o marxistas). (3) Estos proyectos políticos críticos provienen de naciones indígenas, poblaciones afrodescendientes, sectores mestizos e inmigrantes de América del Sur, y de la población latina en los Estados Unidos. (4) Una intervención muy diferente a un simple giro a la izquierda. En este sentido, la opción decolonial puede ser considerada como "[...] la diferencia frente a la expansión del pensamiento monotípico eurocentrado en su diversidad (cristiana, liberal, marxista) (Mignolo 2007c: 214). (RESTREPO y ROJAS, 2010, p. 162).

7 Para compreender a perspectiva teórica e epistemológica do projeto da decolonialidade, sugerimos também a leitura dos artigos "A modernidade é de fato universal?", de Júlio Roberto de Souza Pinto e Walter Mignolo; e "Decolonialidade e perspectiva negra", de Joaze Bernardino-Costa e Ramón Grosfoguel (2016).
} 
campo da historiografia positivista-conservadora e da historiografia crítica espanhola. No segundo tópico explicitamos nossas observações analíticas sobre as representações dos povos indígenas e as narrativas do "descobrimento" e da conquista no ensino de História, presente nos manuais didáticos destinados a professores e alunos da educação secundária espanhola; e, na parte conclusiva, uma visão sucinta sobre representações da América Latina nos manuais didáticos e nos lugares de memória oficial (Centros históricos, monumentos e museus).

\section{A "DESCOBERTA" DO NUEVO MUNDO E AS CONTROVÉRSIAS DA LEYENDA NEGRA}

Como se explica a história do "descobrimento" e da conquista da América na historiografia hispanista e espanhola? Na Espanha, assim como nos demais países da Europa e das Américas, a história do "descobrimento" do Nuevo Mundo continua sendo um capítulo em processo permanente de intepretações e controvérsias. Um capítulo da história humana que poderíamos caracterizar como a primeira fase da globalização moderna e imperialista do mundo ocidental. Na Espanha, no entanto, os atores que inauguraram o discurso da glorificação heroica do "descobrimento" e da conquista encontraram desde o início deste processo uma minoria de intelectuais e religiosos espanhóis que ousaram questionar a legitimidade da conquista e denunciar a "violência banal" empregada pelos conquistadores contra os povos indígenas. Foi a partir desde debate ético-político que se criou o "mito" e a "teoria" da leyenda negra espanhola.

Na historiografia espanhola e hispanista o termo leyenda negra é empregado pelos historiadores/as que aceitam a tese de que o império espanhol foi alvo de um processo de difamação de ordem política, propagado principalmente por holandeses, ingleses e franceses no período da colonização do Nuevo Mundo. Em 1914, o madrilenho Julián Juderías publicou o livro La 
leyenda negra e a editora La Esfera de Los Livros reeditou a obra no ano do centenário da primeira edição. Juderías fundamenta sua visão da leyenda antiespañola com base num amplo estudo de obras estrangeiras que acentuavam e exageravam os aspectos mais negativos da sociedade espanhola. O que é a leyenda negra, segundo Julián Juderías?

\begin{abstract}
¿Qué es, a todo esto, la leyenda negra? ¿Qué es lo que puede calificarse de este modo tratándose de España? Por leyenda negra entendemos el ambiente creado por los fantásticos relatos que acerca de nuestra Patria han visto la luz pública en casi todos los países; las descripciones grotescas que se han hecho siempre del carácter de los españoles como individuos y como colectividad ; la negación, o por lo menos, la ignorancia sistemática de cuanto nos es favorable y honroso en las diversas manifestaciones de la cultura y del arte; las acusaciones que en todo tiempo se han lanzado contra España fundándose para ello en hechos exagerados, mal interpretados, falsos en su totalidad, y finalmente, la afirmación, contenida en libros al parecer respetables y verídicos y muchas veces reproducida, comentada y ampliada en la Prensa extranjera, de que nuestra Patria constituye, desde el punto de vista de la tolerancia, de la cultura y del progreso político, una excepción lamentable dentro del grupo de las naciones europeas (JUDERÍAS, 1914, p. 15).
\end{abstract}

No decorrer do século XX, o tema da leyenda negra se difundiu com maior vigor pela sociedade espanhola, sendo um tema relativamente frequente no âmbito acadêmico, nos meios de comunicação e no espaço escolar. A teoria da "lenda negra" como uma propaganda antiespanhola, que é uma das principais linhas argumentativas do pensamento neoconservador, afronta diretamente a historiografia histórico-crítica produzida nas universidades espanholas. No período da ditadura franquista (1939-1975), esta crítica floresceu com apoio dos intelectuais conservadores e voltou a ressurgir com intensidade no final da década de 1990 e início da primeira década do século XXI.

Atualmente poucos historiadores/as espanhóis seguem a perspectiva histórica delineada por Las Casas. Na sua condição de hispanista francês, 
Joseph Pérez não se mostra pressionado pelo dilema da leyenda negra. Por isso, trouxe para o centro de suas reflexões o debate que deveria orientar todo o campo do pensamento historiográfico com pretensão de uma ética crítica: o histórico debate ético, político e jurídico ocorrido na sociedade espanhola no contexto do "descobrimento" e da conquista da América, no decorrer do Siglo de Oro.

Pérez (2006, p. 203-217) explicita os principais embates da controvérsia de Valladolid e formula uma síntese que pode ser útil para questionar qualquer outra experiência histórica de colonização: ¿Con qué derecho una nación ocupa el territorio de otra y ejerce su tutela sobre los habitantes? Pérez (p. 203) lembra que la sociedad española se planteó esta pregunta desde el principio, desde 1493, cuando los Reyes Católicos le pidieron al Papa que les otorgara autoridad política sobre los territorios descubiertos o por descubrir.

No campo da produção historiográfica espanhola mais recente constatamos um interesse maior pela teoria da leyenda negra do que pela polêmica de Valladolid, e podemos afirmar com relativa segurança que poucos historiadores/as se aventuraram a seguir a linha de interpretação de Joseph Pérez. A ausência maior, no entanto, se constata nos livros didáticos de ensino de História e nos museus de história, inclusive no Museu do Colégio São Gregório de Valladolid, onde ocorreu o histórico embate entre Las Casas e Sepúlveda.

Considerando a sua importância histórica e epistemológica, convém identificar alguns dos elementos mais importantes deste longo período de reflexão e conflito interno da sociedade espanhola. Joseph Pérez reconhece Las Casas como um dos personagens mais influentes deste episódio que foi caracterizado como o "combate pela justiça”, mas ressalta que não foi o primeiro e nem o último a questionar a violência banal da conquista e da colonização.

O debate surgiu a partir das críticas do dominicano Antonio de Montesinos, em seu sermão proferido em 1511 no povoado de Santo Domingo; encontrou respaldo na figura do professor de teologia de Salamanca, o 
dominicano Francisco de Vitoria, e se difundiu por toda a Espanha com a militância de Las Casas e a publicação de sua obra Brevíssima Relação da Destruição das Índias, em 1552. Do outro lado do combate, protagonizaram os colonos-conquistadores e o grande humanista Juan Ginés de Sepúlveda, na condição de advogado dos colonos e da colonização. No campo da mediação e do fogo cruzado, os reis e as altas autoridades eclesiásticas.

O Tribunal de Valladolid foi uma das últimas fases deste longo "combate pela justiça". ${ }^{8}$ Mas afinal, quais foram os principais temas deste "combate"? Apontamos a seguir um resumo das principais questões suscitadas por esta histórica controvérsia ocorrida no contexto inicial da modernidade/colonialidade. Um debate de natureza teológica, filosófica jurídica e epistemológica que deveria se constituir em um capítulo específico em obras historiográficas e didáticas que se aventuram a explicar/ensinar o que foi realmente o "descobrimento" e a colonização da América:

Com que direito um Estado invade um território de outro Estado e impõe sua tutela sobre seus habitantes?

Tem direito os espanhóis de conquistar o Novo Mundo?

Os índios são seres humanos? Eles devem ser considerados súditos do rei ou escravos? Que destino deve ser reservado aos índios?

A encomenda não é uma forma disfarçada de escravidão?

Como se deve interpretar os documentos oficiais que legitimavam e autorizavam a conquista e posse do Novo Mundo?

O que é a guerra justa? Em que condições se pratica a guerra justa?

É o imperador Carlos V dono do mundo? O Papa tem autoridade para conceder direito de propriedade a uma terra que não é sua?

O Requerimento é um recurso jurídico legítimo para tomar posse das terras e bens de outros povos?

Os índios que resistem a conversão ao cristianismo devem ser castigados/escravizados?

É legítimo invocar os pecados contra natureza dos "bárbaros" (incesto,

\footnotetext{
8 Para uma compreensão mais crítica e detalhada do Tribunal de Valladolid, sugerimos a leitura do texto La controversia entre Ginés de Sepúlveda y Bartolomé de Las Casas, de Francisco Fernández Buey (1992), e o livro Aristóteles em Valladolid, de Jorge Luis Gutiérrez (2007).
} 
sodomia, antropofagia, etc.) para justificar a apropriação de sua terra e seus bens?

Pode se falar de uma doação especial de Deus a favor dos espanhóis?

Considerando a falta de legitimidade e insustentabilidade dos argumentos que justificam a conquista e colonização, devem os espanhóis evadirem-se das Índias? (PÉREZ, 2006, p. 203-217).9

Ao refletirmos sobre a história da violência, como sugere Arlete Farge (2011), nos deparamos com as controvérsias em torno da leyenda negra espanhola, uma polêmica inaugurada nos anos iniciais da conquista da América e intensamente presente nestas duas primeiras décadas do século XXI. Dentre as mais recentes, vimos Conquista y destrucción de las Indias (1492-1573), do historiador Esteban Miras Caballos (2009); La sombra de la leynda negra, uma obra coletiva composta de 15 autores e organizada por María José Villaverde Rico e Francisco Castilla Urbano (2016); Imperiofobia y leyenda negra, de María Elvira Roca Barea (2016), e Leyenda Negra, La Batalla sobre la Imagen de España en Tiempo de Lope de Veja, de Antonio Sanchez Jiménez (2016), professor de Literatura Espanhola e especialista da literatura do Siglo de Oro na Université de Neuchâtel.

No âmbito deste artigo não temos condições de explicitar e diferenciar o conteúdo destas obras, mas temos condições de destacar os seus efeitos na atual historiografia e no ensino de história. Ao mesmo tempo em que se estuda e combate a leyenda negra, também se produz um movimento anti-leyenda que inibe a reflexão crítica em relação ao significado histórico da conquista da América. Ou seja, se existe uma "sombra historiográfica” projetada pela leyenda negra contra os espanhóis, existe também uma sombra historiográfica que vem

\footnotetext{
9 Os resultados jurídicos deste debate culminaram na criação das primeiras leis para regulamentar, organizar e "civilizar" o método da colonização. As Leis de Burgos (1512/1513) tinham a pretensão de conter o ímpeto ambicioso e violento dos espanhóis cristãos no Nuevo Mundo, regulamentando a encomenda e proibindo a escravidão dos índios e os maus tratos abusivos. Em 1542 foi instituída as Leyes Nuevas, que ratificava a proibição da escravidão dos indígenas e estabelecia um prazo para fim das encomendas. Em 1545, Carlos V cede à pressão dos colonos-conquistadores e decreta a abolição do artigo 35, o artigo que fixava um prazo para o fim da encomenda (PÉREZ, 2006, p. 207; 216; 217).
} 
sendo projetada há mais de 500 anos contra os povos de Abya Yala.

Na paisagem projetada do Siglo de Oro, enquanto os adversários externos da coroa espanhola se apropriam da obra de Las Casas para fins políticos e ideológicos, setores mais conservadores da sociedade espanhola iniciam um processo de desqualificação e hostilidade contra o frei dominicano e suas obras. Sánchez Jiménez (2016, p. 63) afirma que la importancia de Las Casas en el desarrollo de la Leyenda Negra fue ya apreciada por los españoles del siglo XVII y denunciada por juristas como León Pinelo o Solórzano Pereira, así como por historiadores como Antonio de Solís. Foi assim que começou a surgir na Espanha, afirma Sánchez Jiménez (2016, p. 63), una oposición a la figura de Las Casas que tomaría frecuentemente la forma de argumentos ad hominem, y que generalmente procedía de los sectores más conservadores.

Na Espanha do século XXI, sobretudo nos espaços institucionais onde predomina a visão histórica da "grande" monarquia espanhola (museus, patrimônio histórico, imprensa), a figura de Las Casas está proscrita dos principais lugares de memória, e no âmbito da historiografia acadêmica poucos trabalhos deram razão substancial para sua crítica anticolonialista e pouca relevância científica para sua crítica da violência instituída e praticada contra os povos indígenas do Nuevo Mundo.

Reconhecemos a validez de alguns dos argumentos da perspectiva conservadora de Julián Juderías e seus seguidores da atualidade contemporânea, assim como a importância da contribuição da historiografia crítica que vem desmistificando os estereótipos na história moderna da Espanha. Entretanto, consideramos mais importante ainda equacionar o dilema entre história e mito com base numa ética crítica, a ser construída com ajuda de uma relação epistemológica intercultural onde a voz e visão de mundo dos povos de Abya Yala sejam vistas e ouvidas, uma vez que a teoria da leyenda negra está diretamente relacionada com a invasão e colonização dos territórios indígenas. Uma visão historiográfica que transcenda, inclusive, a crítica teológica e moralista que originou as controvérsias da "lenda negra", pois como 
ressalta o peruano José Carlos Ballón (2005, p. 559):

La crítica moralista contra afán de lucro - sobre la que el clero construyó la leyenda negra de la conquista - no es sino la otra cara de la moneda de la idealización del régimen oligárquico de servidumbre indígena. Con esta crítica al régimen colonial español Acosta inauguró una larga tradición discursiva hispanoamericana de orientación política conservadora y antiliberal $[. ..] .^{10}$

Ao mesmo tempo em que a historiografia da leyenda negra projeta uma luz de esclarecimento sobre os estereótipos negativos produzidos contra o império colonial espanhol, ela também projeta uma sombra em relação à violência colonialista do período moderno, desprezando a crítica epistemológica desenvolvida pelos pensadores da escola de Salamanca. De um modo geral, tanto nos livros didáticos quanto nos espaços oficiais de memória as informações sobre a escola de Salamanca de Francisco de Vitória, assim como sobre a controvérsia de Valladolid entre Las Casas e Sepúlveda, estão ausentes ou são mencionadas de forma breve e superficial.

Mas afinal, por que consideramos importante conferir um lugar de centralidade para a escola de Salamanca? Porque foi nesta escola que se desenvolveu uma ruptura epistemológica e uma crítica radical das bases filosóficas e teológicas que justificavam e legitimavam a dominação colonialista dos impérios europeus. Para o sociólogo Fernando Álvarez-Uría (2015), os debates teológico-políticos e morais ocorridos no século XVI na Universidade de Paris, Universidade de Pádua e, principalmente, na Universidade de Salamanca, estimulado pelo "descobrimento" da América, provocaram uma mudança de mentalidade e de enfoque epistemológico, culminando com a criação da categoria de "gênero humano" e da ideia universal de direitos humanos. Álvarez-Uría (2015, p. 156-157) argumenta que la categoría de género humano permitía sentar las bases mismas de un derecho de humanidad más allá de la

10 José Ballon está se referindo ao Jesuíta José Acosta (1540-1660) e, particularmente, a sua obra Historia natural y moral de las Indias, publicada em Sevilha em 1590. 
diferenciación entre fieles, cristianos y gentiles, permitía, en fin, romper con la división establecida por Aristóteles entre hombres libres y esclavos por naturaleza.

A historiografia da leyenda negra, portanto, não entra no debate éticopolítico e também epistemológico provocado pela escola de Salamanca; prefere concentrar seu campo de investigação nos "estereótipos" criados contra o império espanhol. Reconhecemos e constatamos no âmbito da historiografia espanhola a importância dos estudos da teoria da leyenda negra para uma compreensão da história dos impérios coloniais europeus do período moderno e, particularmente, a história colonial do império espanhol. Entretanto, salientamos que a teoria da lenda negra não pode ser um artifício político, acadêmico ou historiográfico para "encobrir" ou ignorar a violência banal e intrínseca da racionalidade colonizadora, e nem menosprezar a relevante contribuição histórica dos membros mais críticos da Universidade de Salamanca e de Valladolid para os princípios originários e mais democráticos do pensamento moderno.

A partir do final do século XIX, o termo leyenda negra foi aceito e adotado por escritores e historiadores e tornou-se um objeto de estudo regularmente estudado no âmbito das universidades espanholas no decorrer do século XX. Atualmente o tema da leyenda negra vem sendo estudado por historiadores espanhóis e por hispanistas europeus, latino-americanos e estadunidenses; e também por cidadãos espanhóis que se aventuram no campo historiográfico para atender os anseios dos setores mais conservadores, como no caso do escritor Pio Moa, ex-membro do partido comunista espanhol e antifranquista que fez um giro de 180 graus para a extrema direita e se tornou um sucesso editorial (AMPUDIA DE HARO, 2010).

Talvez a forma como Miras Caballos aborda a questão da "conquista da América” pareça muito áspera, como áspera e ambígua era a narrativa irada de Las Casas. Mas ignorar ou minimizar a violência banal de qualquer experiência histórica de conquista e colonização, ou ainda fazer a apologia da conquista 
como um feito glorioso, como vemos na historiografia neoconservadora, é contribuir para a continuidade das "racionalidades do abominável" (FARGE, 2011) e das práticas de "solução final" (ARENDT, 2013) que fomentam esta onda de violência e barbárie que estamos testemunhando neste Nuevo Mundo globalizado da era virtual. Como sugere a historiadora Arlette Farge (2011, p. 35), "o esquema é claro: a coisa não é mais combater a razão-desrazão dos homens no momento em que se exerce a violência, mas analisar a natureza da racionalidade que produz essa violência a fim de transformar seu curso".

\section{O “DESCOBRIMENTO" E A CONQUISTA DA AMÉRICA NOS MANUAIS DIDÁTICOS}

No campo da História da Educação, os estudos de André Chervel fundamentam três importantes conceitos referentes ao espaço educacional moderno: a escola, a cultura escolar e as disciplinas escolares. Na visão do linguista francês, a escola cumpre uma dupla função: a de instrução das crianças e a formação de disciplinas escolares, "vasto conjunto cultural amplamente original que ela secretou ao longo de decênios ou séculos e que funciona como uma mediação posta a serviço da juventude escolar em sua lenta progressão em direção à cultura da sociedade global" (CHERVEL, 1990, p. 200). Na Espanha, Antonio Viñao (2008), com base nos estudos de Chervel e outros pesquisadores da História da Educação, problematiza a relação entre disciplinas escolares e livros didáticos, salientando que "uma coisa é a história dos livros de texto e outra a das disciplinas escolares". Entretanto, ressalta o mesmo, "de um modo ou outro, existe uma relação estreita entre ambas, ainda que não igualitária". Existe uma relativa autonomia entre ambos, mas "a análise dos livros de texto e do material de ensino como produtos pedagógicos e culturais, somente adquirem um sentido histórico pleno quando se inclui no âmbito mais amplo da história das disciplinas, especialmente quando se refere aos níveis secundário e 
superior de ensino" (VIÑAO, 2008, p. 191-192).11

No campo didático-pedagógico, os atuais livros didáticos de Geografia e História das editoras espanholas cumprem os principais indicadores de qualidade exigidos pela política educacional espanhola. ${ }^{12}$ Os capítulos formam uma configuração relativamente coerente entre textos e imagens. A configuração dos capítulos indica que as editoras estão atentas às características da realidade cultural contemporânea e às necessidades dos docentes e alunos, levando em consideração a cultura digital atual e os recursos da tecnologia virtual. As fontes iconográficas recebem um tratamento didático mais coerente e mais crítico; elas interagem e se complementam com as narrativas textuais, com exercícios e reflexões comparativas de épocas distintas. Além da qualidade digital das imagens, os livros apresentam fragmentos de documentos escritos e iconográficos de época, propiciando uma melhor compreensão do uso de fontes históricas e reflexões comparativas.

Em relação à História da América e, particularmente, em relação à história do "descobrimento" e da conquista, no entanto, a visão predominante é demasiadamente eurocentrista e hispanista. ${ }^{13} \mathrm{Na}$ configuração geral dos livros didáticos de ensino de História, a visão que predomina sobre a colonização imperialista do Nuevo Mundo é uma visão positivista, "norteada" pelos conceitos de evolução, civilização e progresso. Neste aspecto, concordamos com a crítica de Harald Welzer (2016, p. 9-10):

${ }^{11}$ Neste texto, não explicitamos nossa revisão referentes aos estudos da disciplina de ensino de História, mas reiteramos que nossa perspectiva analítica abrangeu três aspectos da realidade observada: obras historiográficas (História da América), ensino de História (Espanha e América Latina) e livros didáticos de ensino de História destinados a alunos e professores espanhóis.

12 Por manuais didáticos, compreendemos os livros destinados ao uso de professores e alunos, em sala de aula e em casa, ou seja: os livros "concebidos na intenção, mais ou menos explícita ou manifesta segundo as épocas, de servir de suporte escrito ao ensino de uma disciplina no seio de uma instituição escolar.” (CHOPPIN, 1992 apud BATISTA; GALVÃO; KLINKE, 2002, p. 33).

${ }_{13}$ Para uma visão mais ampla e atual sobre os estudos de história ibero-americana no ensino de história espanhol, recomendamos a leitura dos trabalhos de María del Carmen Gonzáles Muñoz, 2007; José María Gómez Herráez, 2012; Rafael Valls, 2013; 2015. 
[...] A memória da exploração, da escravidão e do extermínio tornouse a vítima de uma amnésia democrática de que estão afetados todos os estados do Ocidente, que não querem recordar que sua riqueza, do mesmo modo que seu poderio, foram construídos ao longo de uma história mortífera.

Observamos analiticamente a história do "descobrimento" e da conquista da América nos livros didáticos de seis editoras: Anaya, Ecir/Grupo Edetania, Santillana, Vicens Vives, SM e Grupo Editorial Edelvives. Optamos por não fazer uma classificação para evitar enquadramentos rígidos e/ou visão fragmentada em relação às perspectivas históricas dos manuais didáticos. Além disso, não comporta no espaço deste artigo descrições específicas das 18 obras analisadas. Por isso, apresentamos a seguir visões e conceitos de algumas delas.

No livro didático da Vicens Vives (2000), ${ }^{14}$ a primeira visão sobre a América aparece na unidade temática La España de los Habsburgo (siglos XVIXVII). Nesta unidade, os temas abordados são: La formación y organización del Estado moderno autoritario; El imperio europeo; El imperio colonial; Sociedad y economía; Cultura y arte, Renacimiento y Barroco. Embora seja uma obra que realmente assume um compromisso com o pensamento crítico e com o ideal de uma sociedade democrática e socialmente justa, percebemos que em relação à América a perspectiva histórica é positivista, como se pode perceber nos termos empregados no capítulo do "descobrimento" e da conquista: El descubrimiento de un Nuevo Mundo; Las grandes conquistas; La organización del imperio colonial.

A narrativa textual explicita "naturalmente" a tradicional visão do "descobrimento" do ponto de vista do conquistador: El descubrimiento del Nuevo Mundo fue obra de un genovés, Cristóbal Colón, a quien los Reyes Católicos facilitaron tres naves y marineros para llevar a cabo el viaje que proponía: llegar a la india navegando hacia Occidente a través del Atlántico.

\footnotetext{
14 Optamos por indicar a referência da citação pela editora e não pelos autores, porque não queremos induzir o leitor a pensar que estamos julgando o mérito ou a competência dos autores. Nosso objetivo maior foi identificar e problematizar visões e conceitos referentes à História da América, nos livros didáticos em sua relação com as obras historiográficas.
} 
(Vicens Vives, 2000, p. 10). As imagens selecionadas também naturalizam e legitimam a conquista do Nuevo Mundo. Tal como nos livros didáticos de outras editoras, vemos um mapa da América Espanhola, localizando e identificando o território e as cidades construídas pelo império colonial; uma imagem ilustrando uma das cenas da conquista, Hernán Cortês num banquete com embaixadores de Montezuma (Museu da América, Madrid). Vemos o desenho retirado da obra Nueva crónica y buen gobierno, do cronista indígena peruano Guamán Poma de Ayala (1615), escrita no início do século XVII, cujo desenho ilustra a condição de servidão de um indígena diante do conquistador espanhol montado em seu cavalo ${ }^{15}$, e na página seguinte uma imagem do plano da cidade de Lima (Peru), em 1687.

No livro didático da Vicens Vives (2000), texto, imagens e atividades de estudo se complementam coerentemente na forma da pedagogia eurocêntrica em relação ao tema do "descobrimento" e da conquista do Nuevo Mundo. O manual sugere atividades de estudo para ensinar as realizações dos conquistadores e suas conquistas:

Observa el mapa y describe en términos geográficos los territorios que llegaron a conquistar los castellanos en el continente americano.

Comenta las primeras conquistas: ¿en qué ámbito geográfico tuvieron lugar? ¿Qué poblaciones se habían fundado antes de 1520?

¿Qué ruta siguió Cortés? ¿Qué territorio conquistó y qué nombre recibió?

Comenta las conquistas hasta mediados del siglo XVI: ¿qué territorios conquistaron desde México? ¿Quién dirigió la expedición que partió de Panamá hacia el Sur en 1531? (VICENS VIVES, 2000, p. 11).16

15 Embora o objetivo seja explicitar uma visão crítica da conquista, não se faz nenhuma referência explicativa sobre a obra de Guamán Poma.

${ }^{16}$ No tópico La América española en el siglo XVIII, o manual didático da Vicens Vives (2000) apresenta alguns dados sobre a estrutura administrativa, sobre a população, as atividades econômicas e o comércio. Informa que a estimativa dos historiadores para a população colonial da América espanhola é de cerca de 15 milhões de habitantes, sendo 46\% indígena, $20 \%$ brancos, $26 \%$ mestiços e $8 \%$ negros. Ensina que a atividade econômica era baseada no 
O manual Historia de España, da editora Ecir/Grupo Edetania (2009), se propõe a mostrar uma história geral e concisa da Espanha, desde a préhistória. Os temas do "descobrimento" e da conquista são ensinados no eixo temático La Edad Moderna, Expansión Ultramarina e Imperio Colonial. Os termos usados para nominar os capítulos são: El descubrimiento de América (p. 38); La conquista de un nuevo mundo (p. 39); La colonización y explotación de las Indias (p. 39); e Hispanoamerica en siglo XVIII.

Como o manual da Ecir explica o "descobrimento" da América? Primeiramente apresenta Cristóvão Colombo como descobridor, mas um descobridor que encontrou um Nuevo Mundo mediante um erro grosseiro, uma vez que seu objetivo era chegar à Índia (Ásia). O capítulo ressalta o erro de Colombo, afirmando que não reconheceu o novo continente mesmo depois das quatro viagens que realizou. Explicita também uma crítica em relação aos conquistadores que almejavam riqueza e poder, cobiça por ouro e prata, e ressalta a violência cometida contra as grandes culturas autóctonas (azteca, inca) y el exterminio del indígena por guerras, trabajos forzados en mina $y$ plantaciones y por enfermedades traídas por los conquistadores (viruela, sarampión, gripe, difteria, tifus...) que diezmaban tribus enteras (ECIR, 2009, p. 39).

O manual da Ecir evoca a figura do Frei Bartalomé de Las Casas para sustentar a crítica da violência colonizadora, pondera a dimensão da violência caracterizada por Las Casas, que estimava em cerca de vinte milhões o número de mortes indígenas, e informa o leitor que as potências europeias rivais ajudaram a propagar a leyenda negra contra a monarquia espanhola, exagerando e singularizando a crueldade dos espanhóis. O manual da Ecir

pacto colonial: a colônia exporta matérias-primas (produtos agrícolas, pecuária e minerais) e compra produtos manufaturados da metrópole. O capítulo destaca o progresso econômico de ambos os lados do Atlântico a partir de algumas medidas liberais. Informa que com a abertura de alguns portos ao livre comércio em 1765 e da promulgação do decreto real de 1778, que permitia a todos os comerciantes espanhóis estabelecer comércio com a América, e com o fechamento da Casa de Contratação em 1790, houve un auge extraordinário del comercio y de algunos puerto españoles. Entretanto, a partir de 1796 una nueva guerra con Inglaterra hizo muy difíciles las rutas atlánticas (VICENS VIVES, 2000, p. 34-35). 
(2009, p. 39) evidencia a dimensão ideológica da leyenda negra, mas reitera que não se oculta una auténtica catástrofe demográfica en la que perecerían tres cuartas partes de los indígenas. De um modo geral, o livro didático da editora Ecir explicita uma visão crítica da colonização, mas os povos indígenas são representados na condição de vítimas.

A História da América que se ensina no manual didático da editora Santillana (2012) também segue o roteiro da historiografia crítica e positivista. Nos capítulos referentes ao "descobrimento" e a conquista, vemos a visão histórica condicionada pelos conceitos de evolução e civilização. No capítulo, vemos um mapa representando as grandes civilizações existentes no final do século XV, estabelecendo uma visão hierarquizada e ocidentalizada. Na primeira página do capítulo em que se apresenta El mundo al inicio de la Edad Moderna o leitor visualiza a localização das civilizações no tradicional mapa que confere um lugar de centralidade para a Europa. O mapa destaca em cores vivas os territórios das grandes civilizações e impérios. Nos demais espaços, cuja área representa mais da metade territorial do planeta, espaço onde viviam as comunidades indígenas do Nuevo Mundo, aborígenes da Austrália e Nova Zelândia, povos tribais da África, nativos asiáticos, esquimós e outros povos de organização comunitária sem Estado e cidade, não há informações e nem visibilidade.

Tal como nos demais manuais, o manual da Santillana usa os conceitos de civilização e império de forma naturalizada, quando não de forma apologética: Durante los siglos XV e XVI, los europeos llevaron a cabo una extraordinaria expansión territorial que les permitió conocer la forma y las dimensiones de la Tierra y la existencia de América y Oceanía. (Santilllana, 2012, v. 2, p. 136); e quando se menciona os bosquimanos e os hotentotes do sul da África, o manual ensina que estes povos estavam en un nível evolutivo similar al de la Prehistoria. (Ibidem, 2012, v. 2, p. 136). No capítulo que aborda a "origem do mundo moderno", o manual didático da editora Santillana apresenta um panorama geral e tradicional do conceito de "descobrimento". A 
narrativa textual, as imagens e as atividades didático-pedagógicas se moldam dentro do paradigma do modelo civilizatório ocidental, orientados pelo conceito de civilização e evolução. Nesse capítulo, explicita-se as causas dos descobrimentos na perspectiva evolucionista: evolução da cartografia, dos instrumentos de navegação e dos novos tipos de embarcações. Vemos o tradicional roteiro que narra as aventuras das explorações portuguesas e castelhanas, el descubrimiento de América por Cristóvão Colombo e o repartimento do mundo entre os reis de Portugal e Castela. O Tratado de Tordesilhas é apresentado na tradicional visão que confere naturalidade e legitimidade ao imperialismo europeu.

\begin{abstract}
Como consecuencia de los descubrimientos, Portugal y Castilla crearan dos grandes imperios ultramarinos. Para evitar problemas entre ellos, se decidió realizar un reparto de las áreas a explorar por cada uno de los dos países, que se plasmó en el Tratado de Tordesillas de 1494 [grifos dos autores]. Se estableció un meridiano que separaba las dos demarcaciones (doc. 5). A Portugal le correspondían las tierras de África y Asia, así como Brasil, que fue descubierto posteriormente. Para Castilla quedara la mayoría de las tierras de América y las islas Filipinas (SANTILLANA, 2012, v. 2, p. 142).
\end{abstract}

Um capítulo de duas páginas sobre as civilizações Maias, Incas e Astecas, e uma visão antropológica desatualizada sobre os povos indígenas das florestas e das planícies, evidencia a perspectiva eurocentrista do manual didático da editora Santillana. Imagens selecionadas no capítulo sobre as três civilizações americanas: mapa identificando a localização dos três impérios; pintura mural Maia que ilustra o ritual de sacrifício de um prisioneiro; imagem de uma máscara Inca de ouro; detalhe em pedra de Montezuma; e as ruínas de Machu Pichu no Peru. No capítulo sobre o "descobrimento", o manual ensina que antes de la llegada de los españoles a América existía en ese continente una gran variedad de culturas a las que se ha dado el nombre de precolombinas [grifo dos autores], porque estaban allí antes del viaje de Cristóbal Colón. Afirma que las más destacadas eran las de los mayas, incas y 
aztecas, que habían desarrollado florecientes civilizaciones; e que, sin embargo, existían muchos otros pueblos que vivían en el continente americano. La mayoría de ellos eran pequeñas tribus con formas de vida muy primitivas (SANTILLANA, 2012, v.2, p. 144). ${ }^{17}$

No manual da Edelvives (2015), a América é apresentada aos alunos na segunda unidade temática, Los inicios de la Edad Moderna. De um modo geral, o conjunto dos temas tratados segue o mesmo roteiro básico das demais editoras: as monarquias autoritárias e a sociedade; a monarquia dos Reis Católicos e o descobrimento da América. A monarquia dos Reis Católicos é representada como uma monarquia autoritária e ao mesmo tempo a monarquia que inicia o processo de formação do Estado hispânico e a expansão atlântica que culminou no "descobrimento" do novo mundo.

No capítulo sobre o "descobrimento" o manual apresenta um conjunto de informações sobre a existência de uma ampla diversidade de povos e culturas, com destaque paras as três grandes civilizações difundidas pelas obras historiográficas - Astecas, Incas e Maias; explicita o projeto de navegação e as viagens de Cristóvão Colombo. Apesar da configuração geral eurocentrista, o manual da Edelvives oferece uma representação cartográfica com a identificação e localização das diversas culturas indígenas que ocupavam a América précolombiana, criando uma oportunidade para que alunos e professores tenham uma dimensão mais intercultural da realidade e condições pedagógicas para problematizar o conceito de "descobrimento". No panorama geral, no entanto, o protagonista do capítulo referente ao "descobrimento" da América é Cristóvão Colombo (EDELVIVES, 2015, p. 51).

Na unidade seguinte - La época de las reformas y la hegemonía hispánica -, o manual da Edelvives (2015) aborda o tema da conquista e colonização. Aqui se repete praticamente as mesmas explicações que os demais

\footnotetext{
17 Nos manuais didáticos tanto quanto nas obras historiográficas, o uso das representações cartográficas continua sendo usado de forma acrítica, ou seja, usa-se o recurso cartográfico para complementar e ilustrar o conhecimento histórico como se um mapa em si seja uma forma de representação neutra e universal do mundo.
} 
livros didáticos, embora de forma mais superficial e esquemática. O manual apresenta um quadro geral da conquista: os objetivos, as causas do domínio espanhol; a conquista dos grandes impérios e a resistência teimosa de algumas tribos, como a oferecida pelos mapuches. Destaca as principais conquistas e os principais conquistadores: Hernán Cortéz, conquistador do império asteca; Pedro de Alvarado, conquistador das cidades maias de Yucatan e Honduras; Francisco Pizarro e Diego de Alamagro, conquistadores do império inca; Pedro Valdivia, conquistador do Chile; Pedro Mendoza, Juan de Ayola e Domigo Martinez de Irala, conquistadores da região do Paraguai e rio da Prata (EDELVIVES, 2015).

O livro de Geografia e História (ESO 3, 2015) da editora Anaya está dividido em três partes: El inicio de la Edad Moderna: Los siglos XV y XVII; El inicio de la Edad Moderna en España y América; El siglo XVII en Europa y España. Conteúdos referentes à América são ensinados nas unidades 1 e 2, sendo que na terceira unidade o manual apresenta as características do Barroco na América. No capítulo sobre Los descubrimientos, o manual destaca as causas de ordem política, econômica, científicas, tecnológicas, religiosas e ideológicas que resultaram no "descobrimento" e conquista da América. Além das tradicionais imagens cartográficas onde se indica as rotas das principais viagens dos "descobrimentos", vemos uma imagem ilustrativa da caravela como um novo modelo de embarcação da época, e os instrumentos de navegação (bússola, astrolábio e quadrante).

Na página seguinte, vemos os retratos de Enrique $O$ Navegante, rei português (1394-1460); Vasco da Gama (1460-1524), o primeiro navegante português a descobrir uma nova rota para a Índia; Cristóvão Colombo (14361506) e Juan Sebastián Elcano (1476-1526), marinheiro espanhol que participou da primeira navegação de volta ao mundo. Como o manual da Anaya explica o "descobrimento" da América? 


\begin{abstract}
El descubrimiento de América se debió a Cristóbal Colón, un marino de posible origen genovés. Su objetivo, basado en el convencimiento de la redondez de la Tierra, era adentrarse en el Atlántico y llegar a la India navegando por el oeste. Primero presentó su proyecto al rey Juan II de Portugal (1484), que lo rechazó. Entonces, lo ofreció a los Reyes Católicos, que lo aceptaron en las Capitulaciones de Santa Fe (1492) (ANAYA, 2015, p. 18).
\end{abstract}

Em relação ao tema do "descobrimento da América", o livro didático da Anaya, tal como os demais livros didáticos analisados, ensina uma perspectiva histórica conservadora e acentuadamente eurocêntrica. A narrativa textual é "naturalizada" e desprovida de problematizações reflexivas. Quando fala do Tratado de Tordesilhas, ou seja, a "repartição do novo mundo" pelas duas grandes potencias imperialistas do século XVI, afirma que El descubrimiento de nuevas tierras más allá del océano tuvo un impacto inmediato en toda Europa; e que Los Reyes Católicos recibieron del papa la soberanía de las Indias, y para evitar conflictos con Portugal, delimitan sus respectivas áreas de influencia en el Tratado de Tordesillas (1594); e segue outras informações sobre a localização geográfica das linhas imaginárias do tratado.

Hernán Cortez é apresentado como o conquistador do México (civilização Asteca) e Pizarro, do Peru (civilização Inca). Uma imagem de um soldado espanhol portando uma arma de fogo e em posição de ataque é usada para ilustrar a superioridade bélica dos conquistadores. Na página ao lado, vemos um conjunto de mapas e ruínas das sociedades Asteca e Inca para mostrar o que foi conquistado. Na primeira metade da página, um mapa indicando e localizando as etapas da conquista; na parte inferior, dois pequenos mapas e duas imagens (pirâmide Asteca e ruínas da cidade de Machu Pichu) para complementar as informações sobre a realidade cultural do que foi conquistado (ANAYA, 2015, p. 46-47).

Todos os livros didáticos apresentam um conjunto de atividades complementares para reforçar, complementar e ampliar os conhecimentos ensinados. O livro didático da editora Anaya (ESO 3, 2015) também apresenta 
um conjunto de atividades complementares com o objetivo de desenvolver uma visão crítica sobre a colonização da América. Na parte referente ao "informe gráfico", por exemplo, o manual sugere leituras e pesquisas sobre as encomendas e suas consequências; leitura e interpretação das denúncias realizadas pelos freis Antonio de Montesinos e Bartolomé de Las Casas; o capítulo apresenta imagens que ilustram a prática da encomenda e a cristianização dos indígenas; sugere pesquisa sobre a criação das Leis das Índias e sobre as interpretações conflitivas da colonização que resultaram na leyenda negra anti-espanhola.

Mesmo considerando a preocupação com o ensino de uma visão histórica crítica, notamos, no entanto, a configuração de uma "visão crítica" dentro dos limites da geografia epistemológica da modernidade europeia. Visão crítica, aliás, que fica praticamente obscurecida pela forma de ensinar uma visão de História da América condicionada pela concepção do Siglo de Oro da monarquia espanhola e pelos marcos teóricos da epistemologia eurocentrista.

\section{CONSIDERAÇÕES FINAIS}

Qual o lugar da História da América (América Latina e de Abya Yala) no ensino de História na educação secundária espanhola? Esta foi a questão principal que orientou nosso campo de pesquisa. De acordo com nossos estudos bibliográficos e nossa pesquisa de campo, a História da América que se explicita na produção historiográfica e se ensina nos espaços educativos da sociedade espanhola sofre a influência condicionante de dois grandes "obstáculos epistemológicos"18: o eurocentrismo e o etnocentrismo espanhol (hispanismo neoconservador).

Reconhecemos e concordamos com os estudos que evidenciam uma

${ }^{18}$ Empregamos o termo "obstáculo epistemológico" no sentido proposto por Gaston Bachelard (1996). 
melhoria significativa na práxis educativa do ensino de História iberoamericana, após a ditadura franquista. Entretanto, tal como no Brasil, a estrutura do ensino da História espanhola está condicionada pela geografia do conhecimento eurocentrista, sedimentada numa estrutura curricular que legitima as grandes conquistas imperiais do passado e justifica a racionalidade colonialista que devastou a diversidade cultural de dois continentes: Abya Yala/América e África.

Em relação à historiografia universitária espanhola, percebemos que a mesma se fundamenta de forma consistente em fontes documentais diversas e difunde uma visão histórica crítica, diferentemente da historiografia positivista que tende a fazer uma apologia da grandeza da monarquia espanhola do Siglo de Oro. Entretanto, quando se adota o ponto de vista histórico dos povos de Abya Yala ou mesmo da América Latina, a perspectiva histórica crítica espanhola ainda se encontra demasiadamente condicionada pelo eurocentrismo. $\mathrm{O}$ mesmo se pode afirmar em relação aos manuais didáticos contemporâneos, onde a História da América aparece apenas como um capítulo complementar da História da Espanha.

Nos últimos anos ressurgiu com vigor uma historiografia saudosista que procura preservar e valorizar a memória do grande império espanhol dos séculos XVI e XVII, juntamente com a revitalização de uma imagem positivada do franquismo. Vemos, então, uma Espanha glorificada nos lugares de memória em sintonia com a produção editorial de uma memória historiográfica que busca enaltecer as grandes conquistas da Monarquia Espanhola do Siglo de Oro. Ao mesmo tempo em que se enaltece o passado glorioso, os expoentes mais prestigiados desta historiografia "revisionista" (não acadêmica) procuram deslegitimar as visões críticas que supostamente criaram a leyenda negra española, desqualificando a historiografia acadêmica que projeta luz sobre a face mais obscura do imperialismo espanhol do Siglo de Oro. Este fenômeno neoconservador, que "com maior ou menor nível de formalização" constitui o arsenal dos "argumentos revisionistas enquanto revitalização das velhas teses 
franquistas", explica Ampudia de Haro (2010, p. 206), "voltou a surgir em diferentes publicações de inegável sucesso editorial.”

Nos Centros históricos e nos museus, os turistas apreciam a arquitetura imponente, as obras de arte e os grandes monumentos do passado "glorioso" da monarquia espanhola. Nos centros históricos das pequenas e grandes cidades, os estrangeiros e as novas gerações de alunos da cultura escolar espanhola, ficam admirados com a grandeza e beleza das catedrais e dos palácios ornados com ouro e prata. Nestes espaços, no entanto, não há informações sobre a origem das riquezas naturais (ouro, prata, madeira) que ornamentam e seduzem qualquer visitante, muito menos sobre os trabalhadores que os construíram. Ainda nos centros históricos, os visitantes tem a oportunidade de conhecer e admirar a beleza das praças maiores, dos jardins, dos museus e dos monumentos da nobreza espanhola e da conquista da América. No interior dos museus, monumentos, artefatos, documentos e obras de arte complementam a memória "gloriosa" do Siglo de Oro.

\section{REFERÊNCIAS}

AMPUDIA DE HARO, Fernando. Uma aproximação ao revisionismo em Espanha: o fenómeno Pío Moa. Ler história, n. 58, p. 203-224, 2010. Disponível em: https://journals.openedition.org/lerhistoria/1247. Acesso em: 09 jan. 2019.

ARENDT, Hannah. Eichmann em Jerusalém: um relato sobre a banalidade

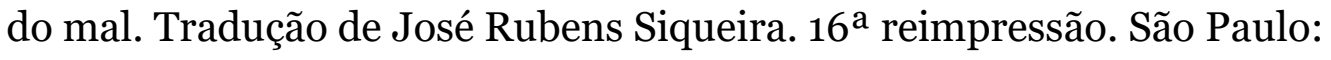
Companhia das Letras, 2013.

BATISTA, Antônio Augusto Gomes; GALVÃO, Ana Maria de Oliveira; KLINKE, Karina. Livros escolares de leitura: uma morfologia (1866-1956). Revista brasileira de educação, n. 20, p. 27-47, p. 27-47, maio/jun./jul./ago. 2002. Disponível em: http://www.scielo.br/pdf/rbedu/n20/n20ao3. Acesso em 15 fev. 2019.

BELLATTI, Ilaria et al. Los contenidos curriculares de historia en los países del 
ámbito iberoamericano: una aproximación cuantitativa. In: PRATS, Joaquín; VALLS, Rafael; MIRALLES, Pedro (Eds.). Iberoamérica en las aulas: qué estudia y qué sabe el alumnado de educación secundaria. Lleida, ES: Editorial Milenio, 2015. p. 21-100.

BERNARDINO-COSTA, Joaze; GROSFOGUE, Ramón. Decolonialidade e perspectiva negra. Revista Sociedade e Estado - v. 31, n. 1, p. 15-24, jan./abr. 2016. Disponível em: http://www.scielo.br/pdf/se/v31n1/0102-6992se-31-01-00015.pdf. Acesso em: 15 fev. 2017.

DUSSEL, Enrique. El encubrimiento del otro: hacia el origen del mito de la modernidad. La Paz: UMSA. Facultad de Humanidades y Ciencias de la Educación, Plural Editores,1994. Disponível em: http://bibliotecavirtual.clacso.org.ar/clacso/otros/20111218114130/1942.pdf. Acesso em: 09 maio 2016.

DUSSEL, Enrique. 14 tesis de ética: hacia la esencia del pensamiento crítico. Madrid: Editorial Trotta, 2016.

FARGE, Arlette. Lugares para a história. Tradução de Fernando Scheibe. Belo Horizonte: Autêntica Editora, 2011 (Coleção História e Historiografia).

FREIRE, Paulo; SCHOR, Ira. Medo e ousadia: o cotidiano do professor. Trad. Adriana Lopes. 2. ed. Rio de Janeiro: Paz e Terra, 1986.

FREIRE, Paulo. Educação como prática da liberdade. 32 reimpressão. Rio de Janeiro: Paz e Terra, 2009.

GÓMEZ HERRÁEZ, José María. América Latina en la enseñanza española durante el siglo XX Aspectos económicos y sociales. Revista chilena de economía y sociedad, 5 (1-2), p. 14-25, dic. 2012. Disponível em: http://rches.blogutem.cl/files/2013/o7/arto2_vol5.pdf. Acesso: em 21 out. 2016.

JUDERÍAS, Julián. La leyenda negra de España. Reedición a cargo de Luis Español Bouché. Madrid: La Esfera de los Libros, 2014.

LANDER, Edgardo (Org.) A colonialidade do saber: eurocentrismo e ciências sociais. Perspectivas latino-americanas. Buenos Aires: Clacso, 2005. Disponível em: http://biblioteca.clacso.edu.ar/ar/libros/lander/pt/lander.html. Acesso em: 14 jul. 2017.

LAS CASAS, Frei Bartolomé de. O paraíso destruído: brevíssima relação da destruição das Índias. Tradução de Heraldo Barbury. Porto Alegre: L\&PM, 
2001.

LISBOA, Armando de Melo. De América a Abya Yala: semiótica da descolonização. Revista de educação pública, v. 23, n. 53/2, p. 501-531, 2014. Disponível em:

http://periodicoscientificos.ufmt.br/ojs/index.php/educacaopublica/article/vie w/1751. Acesso em: o5 dez. 2016.

MIGNOLO, Walter D. La idea de América Latina: la herida colonial y la opción decolonial. Traducción de Silvia Jawerbaum y Julieta Barba. Barcelona: Gedisa/BIP-Biblioteca Iberoamericana de Pensamiento, 2007.

MIRAS CABALLOS, Esteban. Conquista y destrucción de las Indias (1492-1573). Sevilla: Muñoz Moya, 2009.

MIRAS CABALLOS, Esteban. El 12 de octubre, ¿Genocidio o Leyenda Negra? Publicado em 12 out. 2016. Disponível em:

http://estebanmiracaballos.blogia.com/temas/historia-de-america.php. Acesso em: 14 out. 2016.

PORTO-GONÇALVES, Carlos Walter. Entre América e Abya Yala - tensões de territorialidades. Desenvolvimento e meio ambiente, Curitiba, PR, Editora UFPR, n. 20, p. 25-30, jul./dez. 2009. Disponível em:

http://revistas.ufpr.br/made/article/view/16231. Acesso em o6 fev. 2017.

PRATS, Joaquín; VALLS, Rafael; MIRALLES, Pedro (Ed.). Iberoamérica en las aulas: qué estudia y qué sabe el alumnado de educación secundaria. Lleida, ES: Editorial Milenio, 2015.

QUIJANO, Aníbal. Colonialidade do poder, eurocentrismo e América Latina. In: LANDER, Ed. (Org.). A colonialidade do saber: eurocentrismo e ciências sociais. Perspectivas latino-americanas. Buenos Aires: Clacso, Consejo Latinoamericano de Ciencias Sociales, 2005, p. 117-142. Disponível em: http://biblioteca.clacso.edu.ar/clacso/sursur/20100624103322/12_Quijano.pdf. Acesso em: 26 jul. 2016.

RESTREPO, Eduardo; ROJAS, Axel. Inflexión decolonial: fuentes, conceptos y cuestionamientos. Popayán, Colombia: Universidad del Cauca, 2010. Disponível em:

https://biblio.flacsoandes.edu.ec/catalog/resGet.php?resId=43099. Acesso em: out. 2018.

ROCA BAREA, María Elvira. Imperiofobia y leyenda negra: Roma, Rusia, Estados Unidos y el Imperio español. Madrid: Ediciones Siruela, 2016 
(Biblioteca Ensayo).

SARANGO, Luis Fernando. Universidad intercultural de las nacionalidades y pueblos indígenas «Amawtay Wasi». Ecuador/Chinchaysuyu. In: MATO, Daniel (coord.). Instituciones interculturales de Educación Superior en América Latina. Procesos de construcción, logros, innovaciones y desafíos. Caracas: Instituto internacional de la Unesco para la Educación Superior en América Latina y el Caribe (Unesco-Iesalc), 2009. p. 191-214. Disponível em: www.iesalc.unesco.org.ve/dmdocuments/ecuadoruniamawtay2.pdf. Acesso em: 06 fev. 2017.

VALLS, Rafael. España. La presencia de los países de Iberoamericanos en los manuales de historia de la Educación Secundaria Obligatoria española: existe ya una dimensión iberoamericana? In: PRATS, Joaquín; VALLS, Rafael;

MIRALLES, Pedro (Ed.). Iberoamérica en las aulas: qué estudia y qué sabe el alumnado de educación secundaria. Lleida, ES: Editorial Milenio, 2015.

VALLS, Rafael. Iberoamérica en la enseñanza española de la historia. Práxis Educativa, Ponta Grossa, v. 8, n. 2, p. 351-374, jul./dez. 2013. Disponível em: http://www.revistas2.uepg.br/index.php/praxiseducativa. Acesso em: 16 abr. 2015 .

VILLAVERDE RICO, María José; CASTILLA URBANO, Francisco (Org.). La sombra de la leyenda negra. Madrid: Tecnos/Grupo Anaya, 2016.

VIÑAO, Antonio. A história das disciplinas escolares. Revista brasileira de história da educação, n. 18, p. 173-215, set./dez. 2008. Disponível em: http://periodicos.uem.br/ojs/index.php/rbhe/issue/view/1465/showToc. Acesso em: 15 fev. 2019.

VIÑAO, Antonio. Escuela para todos: educación y modernidad en la España del siglo XX. Madrid: Marcial Pons/Ediciones de Historia, 2004.

WELZER, Harald Welzer. A guerra da água: por que mataremos e seremos mortos no século 21. Tradução de William Lagos. 2. ed. São Paulo: Geração Editorial, 2016. 


\section{Livros Didáticos de Ensino de História e Geografia (Espanha)19}

ALMIÑANA, Eugenio García et al. Historia de España. Bachillerato 2. Madrid: Ecir Editorial, Grupo Edetania, 2009.

BURGOS ALONSO, Manuel; MUÑOZ-DELGADO, Ma Concepción. Geografía e historia. ESO 3. Madrid: Anaya, 2015.

FERNÁNDEZ, Antonio Brandi et al. Horizonte. Historia. Bachillerato 2. Barcelona: Vicens Vives, 2000.

FERNÁNDEZ, Antonio Brandi; RUIZ, Teresa Grence et al. Geografía e historia. Región de Murcia. 2. ESO. Madrid: Santillana, Proyecto Los caminos del saber, v. 1, 2012.

FERNÁNDEZ, Antonio Brandi; RUIZ, Teresa Grence et al. Geografía e historia. Región de Murcia. 2. ESO. Madrid: Santillana, Proyecto Los caminos del saber, v. 2, 2012.

FERNÁNDEZ, Antonio Brandi; RUIZ, Teresa Grence et al. Geografía e Historia. Región de Murcia. 2. ESO. Madrid: Santillana, Proyecto Los caminos del saber, v. 3, 2012.

GIMÉNEZ RUIZ, José Antonio et al. Historia (geografía e historia). ESO 3. Zaragoza, ES: Grupo Editorial Edelvives, 2015.

SEBASTIÁN, M. García et al. Geografía e historia. 3.2. Aula 3D. Educación Secundaria. Madrid: Vicens Vives, 2015.

\footnotetext{
CARLOS RENATO CAROLA é professor do Programa de Pós-graduação em Educação e Departamento curso de História da Universidade do Extremo Sul Catarinense (Unesc); Doutor em História pela Universidade de São Paulo (USP, 2004).

E-mail: crc@unesc.net

(iD) http://orcid.org/0000-0003-0073-9588
}

19 Esta é a relação dos manuais citados no corpo do texto. No âmbito da pesquisa foram analisados 18 manuais editados no período de 2000 a 2015, e três da década de 1990. 
RAFAEL VALLS MONTÉS es profesor da Facultad de Magisterio, Departamento de Didáctica de las Ciencias Experimentales y Sociales, Universidad de Valencia (España); Doctor en Historia, Universidad de Valencia, 1990.

E-mail: rafael.valls@uv.es

(iD) http://orcid.org/0000-0002-3688-0367

Recebido em: 04 de maio de 2018

Aprovado em: 06 de maio de 2019

Revista História da Educação - RHE

Associação Sul-Rio-Grandense de Pesquisadores em História da Educação - Asphe

Artigo de acesso aberto distribuído nos termos de licença Creative Commons. 